\title{
Potential of granulated modified nanozeolites Y for MTBE removal from aqueous solutions: Kinetic and isotherm studies
}

\author{
S.K. Ghadiri ${ }^{1}$, R. Nabizadeh ${ }^{1}$, A.H. Mahvi ${ }^{1,2,3, *}$, S. Nasseri ${ }^{1}$, A.R. Mesdaghinia ${ }^{1}$, \\ S.S. Talebi ${ }^{4}$ \\ ${ }^{1}$ Tehran University of Medical Sciences, School of Public Health, Tehran, Iran \\ ${ }^{2}$ Tehran University of Medical Sciences, Center for solid Waste Research, Institute for Environmental Research, Tehran, Iran \\ ${ }^{3}$ Tehran University of Medical Sciences, National Institute of Health research, Tehran, Iran \\ ${ }^{4}$ Islamic Azad University, Department of statistics, Abhar Branch, Abhar, Iran \\ "Corresponding author: e-mail: ahmahvi@yahoo.com
}

\begin{abstract}
Adsorption of methyl tert-butyl ether (MTBE) from aqueous solutions by granulated modified nanozeolites $\mathrm{Y}$ was investigated. Nanozeolite $\mathrm{Y}$ powders were converted into granulated zeolites and subsequently modified with two cationic surfactants $\left(20 \mathrm{mmol} / \mathrm{dm}^{3}\right)$, to be used as adsorbent. Granulated nanozeolites were characterized by BET surface area analysis, elemental analysis and X-ray diffractometer. Hexadecyltrimethylammonium (HDTMA-Cl) modified granulated zeolite had more effective performance than N-cetylpyridinium bromide (CPB) modified granulated zeolite. The most conventional adsorption isotherms and kinetic models were applied to describe MTBE adsorption and reaction dynamic, respectively. The equilibrium sorption data fitted the Langmuir 2 isotherm model and the kinetic study was followed the pseudo-second-order model. The maximum adsorption capacities for HDTMA-Cl modified zeolite and CPB modified granulated zeolite were 333.33 and $142.8 \mathrm{mg} / \mathrm{g}$, respectively as calculated by the Langmuir model. This study demonstrated that the removal of mtbe by granulated modified nanozeolites $\mathrm{Y}$ is a promising technique.
\end{abstract}

Keywords: Methyl tert-butyl ether (MTBE), Nanozeolites, Granulation, Modification, Adsorption isotherm, Adsorption kinetic.

\section{INTRODUCTION}

Methyl tert-butyl ether (commonly referred to as MTBE) is the most common anti-knocking agent used to promote combustion efficiency ${ }^{1}$. From a drinkingwater perspective, one of the most important aspects of MTBE is its objectionable taste and odor. Due to its high water solubility, low Henry's law constant, and slow biodegradability, MTBE is the relatively stable and resistant compound in the environment ${ }^{2}$. However, with the widespread use of MTBE, it has become one of the most frequently detected underground water pollutants ${ }^{3,4}$. MTBE concentrations in water supplies may be reduced by air stripping, photocatalytic degradation, filtration, advance oxidation, and adsorption5. Among the MTBE removal processes, adsorption is believed to be the most economic and feasible method for water treatment. In addition, absence of undesirable byproducts in drinking water is the advantage of using adsorption processes ${ }^{6}$.

Zeolites are crystalline materials and their structure consists of hydrated aluminosilicates of metals from group I and group II elements. Structurally the zeolites are framework aluminosilicates which are based on an infinitely extending three-dimensional network of $\left(\mathrm{AlO}_{4}\right)^{-5}$ and $\left(\mathrm{SiO}_{4}\right)^{-4}$ tetrahedral units linked to each other by sharing all of the oxygen. This framework causes negative structural charges and a high cation exchange capacity (CEC). These characteristics have made the zeolites excellent adsorbent materials. Zeolites are divided into two main classes, namely, mineral such as clinoptilolite and mordenite and the synthetic zeolite such as zeolite A, $\mathrm{X}$ and $\mathrm{Y}$. Synthetic zeolite $\mathrm{Y}$ exhibits a structure similar to naturally occurring faujasite types which has a 3-dimensional pore structure. The pore diameter of zeolite $\mathrm{Y}$ is $7.4 \AA$ since the aperture is defined by a 12 member oxygen ring, and leads into a larger cavity of diameter $12 \AA$. The cavity is surrounded by ten sodalite cages connected on their hexagonal faces ${ }^{7}$.

Nanozeolites particles have higher available surface area than the typical zeolites. This availability decreases the diffusion path length and on the other hand, it can increase the adsorption feasibility ${ }^{8}$.

In order to utilize nanozeolites particles as water treatment media in various industrial applications, granulation of nanozeolites with a glue-like media (sodium alginate) and consequently removal of this binder media by calcination is highly desired. This method is a suitable shaping process which would be able to assemble these powders into stable aggregates without losing their original characteristics ${ }^{\mathbf{9 1 1}}$.

There have been various attempts to improve the surface quality and characteristics of the zeolites by modifying them with different techniques ${ }^{12}$. Modification of zeolites and altering their surface chemistry using cationic surfactants make the modified zeolites suitable for the adsorption of anions and organic materials such as petroleum monoaromatics including benzene, toluene, ethylbenzene, and xylenes ${ }^{13}$ and $\mathrm{MTBE}^{14}$.

In this study, a synthetic type nanozeolite $\mathrm{Y}$ was granulated by a simple and novel method for the preparation of uniform nanozeolite microspheres by utilizing sodium alginate as an external template. Then the granulated nanozeolites were modified by two cationic surfactants, HDTMA-Cl and CPB. The structural characteristics of the adsorbents were studied. The adsorption process of MTBE by the mentioned adsorbents was investigated. Finally, the kinetics and isotherms for MTBE adsorp- 
tion onto the granulated modified nanozeolites $\mathrm{Y}$ were studied in single solutions.

\section{EXPERIMENTAL SECTION}

\section{Chemicals and Materials}

All the chemicals used in this study were of analytical grade. $\operatorname{MTBE}\left(\mathrm{C}_{5} \mathrm{H}_{12} \mathrm{O} ; \mathrm{w}=88.15\right)$, with $>99 \%$ purity (HPLC grade), supplied by Merck Company, was used as adsorbate. The MTBE solutions were prepared by deionized water and all adsorption experiments were carried out at room temperature $\left(20^{\circ} \mathrm{C}\right)$ in batch mode at constant $\mathrm{pH}$ of 7.1. Deionized water was used everywhere in this work. Sodium alginate was purchased from Sigma-Aldrich and used as an external template in the granulation of nanozeolites. Two types of cationic surfactants, HDTMA-Cl and CPB were used for the modification of zeolites. Both surfactants used in this research were obtained from Merck Company. Prior to any test, all of the instruments used in this study were washed by hot tap water, dichloromethane and deionized water respectively, and then dried at $100^{\circ} \mathrm{C}$ for $45 \mathrm{~min}$. The adsorbent used in this study, nanozeolites Y powder (50-100 nm), was obtained from Neutrino Company.

\section{Preparation of Synthetic Solution}

A stock solution of MTBE $\left(1 \mathrm{~g} / \mathrm{dm}^{3}\right)$ was prepared by pouring pure MTBE $\left(1.350 \mathrm{~cm}^{3}\right)$ into the distilled water $\left(1000 \mathrm{~cm}^{3}\right)$, and the solution was used for further experimental solution preparation. The concentrations, ranging from 1 to $200 \mathrm{mg} / \mathrm{dm}^{3}$, were prepared by stock solution. The $\mathrm{pH}$ solution was adjusted using $0.1 \mathrm{M} \mathrm{HCl}$ or $0.1 \mathrm{M} \mathrm{NaOH}$ before mixing the adsorbent and the MTBE solution.

\section{Adsorbents Preparation}

In this step for the use of nanozeolite Y powder for the adsorption of MTBE, we used a novel shaping process developed by our group that named granulation ${ }^{11,15}$. In this regard sodium alginate has been used as an external template and to increase the mechanical resistance of granules a binder material such as clay was added to nanozeolite powder. In this method for the preparation of granulated nanozeolite $\mathrm{Y}$ initially two grams of nanozeolite powder were blended with clay (20 wt \%) that poured in $5 \mathrm{~cm}^{3}$ of distilled water and $15 \mathrm{~min}$ were subjected to intense ultrasonic waves $(135 \mathrm{kHz})$. And for the preparation of a $2 \%$ by weight of sodium alginate gel, $2 \mathrm{~g}$ of sodium alginate added to $98 \mathrm{~g}$ of water and then was well stirred (150 rpm).

In the next stage, the mixture of nanozeolite and clay was added to sodium alginate gel. This slurry-like mixture was mixed with a magnetic agitator $(150 \mathrm{rpm})$. For the formation of granules, the above mentioned slurry consisting of zeolite, sodium alginate, clay and water was poured into a $0.1 \mathrm{M}$ solution of barium chloride and after $2 \mathrm{~h}$ was washed with distilled water, dried at room temperature, and then through calcinations process the alginate was completely volatized out and left behind spherical granules. The influence of different temperatures and the duration of calcinations was investigated. But finally from the comparison of XRD patterns between the granulated nanozeolites and nanozeolite powder we chose the best calcination condition of $600^{\circ} \mathrm{C}$ temperature and $5 \mathrm{~h}$ duration of calcinations. After the calcination process the granules were sieved to the size of 250-420 $\mu \mathrm{m}$ in order to have a rational comparison of granules chosen for further experimental tests.

\section{Instruments}

The granulated nanozeolites were characterized by BET surface area analysis (Micromeritics Gemini, 2360), X-ray fluorescence (XRF) (Oxford, ED2000) and X-ray diffractometer (XRD, model: XD-5A, Shimadzu). For surface morphology investigation of the zeolites, scanning electron microscopy (SEM, model: XL-30, Philips) was used. Finally, the produced granules were sieved to $0.25-0.42 \mathrm{~mm}$ (ASTM sieve size no. 35-60). MTBE concentration in water was measured using a Varian Gas Chromatograph with a flame ionization detector and Combipal Headspace auto-sampler system (CP-3800, Varian, Australia). For the determination of the solution $\mathrm{pH}$, a Metrohm pH meter (827 pH lab, Switzerland) was used. To shake the mixtures a reciprocating shaker was utilized.

\section{Modification of Adsorbents}

The granulated nanozeolite $\mathrm{Y}$ were treated using HDTMA-Cl (GMN-Y\#1) and CPB (GMN-Y\#2) solutions with the initial concentration of $20 \mathrm{mmol} / \mathrm{dm}^{3}$ that were desirable concentrations according to our recently work $^{\mathbf{1 4}}$. In this regard, $5 \mathrm{~g}$ of the granulated zeolite was added to a $125 \mathrm{~cm}^{3}$ polyethylene bottle with 100 $\mathrm{cm}^{3}$ of HDTMA-Cl or CPB solutions. Then the bottles were stirred in a reciprocating shaker $\left(20.0 \pm 0.5^{\circ} \mathrm{C} ; 150\right.$ $\mathrm{rpm}$ ) for two days. The obtained granulated modified nanozeolites Y complex was separated from the mixture by vacuum filtration and washed out several times with deionized water. The modified zeolites were dried in ambient air for two days and stored for further use.

\section{Concentrations and Adsorption Procedure}

The ability of GMN-Y for the removal of MTBE from aqueous solutions was carried out by a batch technique at room temperature $\left(20.0 \pm 0.5^{\circ} \mathrm{C}\right)$. The container was a $125 \mathrm{~cm}^{3}$ Teflon-sealed screw cap amber glass with $100 \mathrm{~cm}^{3}$ solution containing, 1, 10, 20, 50, 100 and 200 $\mathrm{mg} / \mathrm{dm}^{3}$ of MTBE. Then $5 \mathrm{~g} / \mathrm{dm}^{3}$ of each previously prepared adsorbent (i.e. GMN-Y\#1 and GMN-Y\#2) was added to the solution and the bottles were shaken on a reciprocating shaker $(150 \mathrm{rpm})$ for $24 \mathrm{~h}$ (the time that was found to be sufficient to reach the adsorption equilibrium based on our previous works). After 10 minutes of sedimentation, the supernatants were put into $10 \mathrm{~cm}^{3}$ headspace vials. The concentrations of MTBE in the supernatant solutions before and after adsorption were analyzed using a VARIAN gas chromatograph with a flame ionization detector and a combipal headspace auto sampler system. All adsorption tests were doubled run and the averages are reported. Blank samples were also carried out using the same conditions except for the presence of the adsorbent. The experimental blanks showed no significant losses of MTBE due to volatilization and adsorption to bottle walls. The adsorption capacity of MTBE at equilibrium conditions was determined as 
below:

$$
q_{e}=\frac{\left(C_{i n}-C_{t}\right) \times V}{W}
$$

Where:

$\mathrm{q}_{\mathrm{e}}$ is the MTBE adsorption capacity (milligrams of MTBE per gram of adsorbent), $C_{i n}$ and $C_{t}$ are the initial and equilibrium concentrations of MTBE, respectively (milligrams per $\left.\mathrm{dm}^{3}\right), \mathrm{V}$ is the solution volume $\left(\mathrm{dm}^{3}\right)$ and $\mathrm{W}$ is the dry weight of the adsorbent (gram).

\section{Adsorption Isotherm Studies}

Adsorption isotherm experiments were carried out in $125 \mathrm{~cm}^{3}$ sealed amber bottles at room temperature on a reciprocating shaker $(150 \mathrm{rpm})$ for $24 \mathrm{~h}$ to reach adsorption equilibrium. The two adsorbents (GMN-Y\#1 and GMN-Y\#2) with a constant mass of $0.5 \mathrm{~g}$ were mixed with $100 \mathrm{~cm}^{3}$ of MTBE solutions by different concentrations of 1, 10, 20, 50, 100 and $200 \mathrm{ppm}$. After the 10 minutes sedimentation, samples of $5 \mathrm{~cm}^{3}$ were collected from the supernatant and were analyzed for residual MTBE concentration.

\section{Adsorption Kinetic Studies}

Adsorption kinetics study was done in order to test the relationship between contact time and MTBE adsorption. This step was performed by shaking $0.5 \mathrm{~g}$ of each adsorbent into $100 \mathrm{~cm}^{3}$ of MTBE solution (50, 100 and $\left.200 \mathrm{mg} / \mathrm{dm}^{3}\right)$. The mixture was constantly stirred by a reciprocating shaker at a speed of $150 \mathrm{rpm}$ for 1 to $24 \mathrm{~h}$. The residual concentration of MTBE in the supernatants was analyzed finally.

\section{RESULTS AND DISCUSSION}

\section{Adsorbent Characterization}

The chemical composition of nanozeolite $\mathrm{Y}$ was $\mathrm{SiO}_{2}$ $43.35 \%, \mathrm{Al}_{2} \mathrm{O}_{3} 18.14 \%, \mathrm{Na}_{2} \mathrm{O} 9.65 \%, \mathrm{TiO}_{2} 1.08 \%$ and LOI $23.56 \%$. Fig. 1 and 2 depict the XRD patterns of

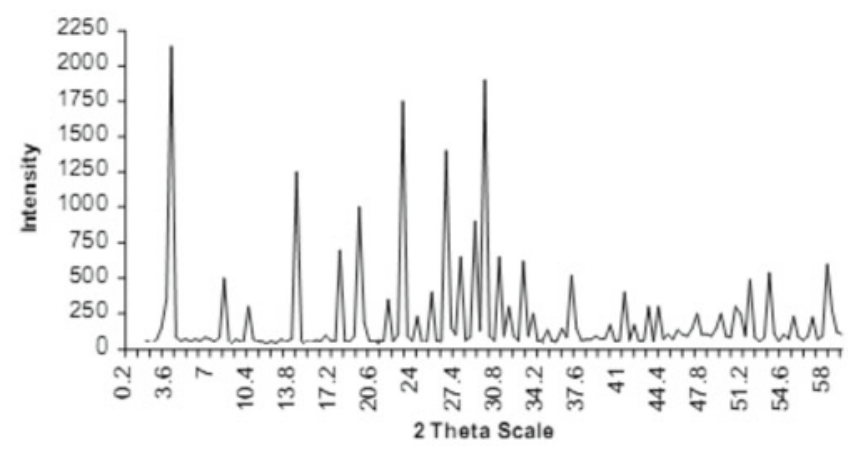

Figure 1. XRD pattern of nanozeolite $\mathrm{Y}$

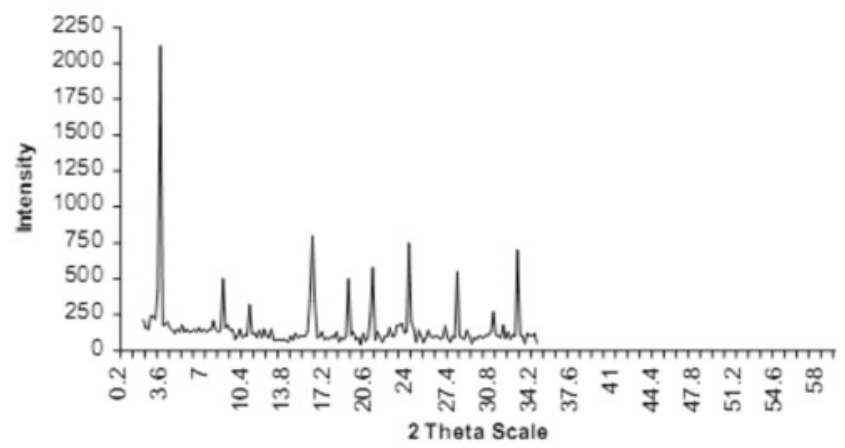

Figure 2. XRD patterns of granulated nanozeolites $\mathrm{Y}$ nanozeolite $\mathrm{Y}$ and produced granules at different temperatures of calcination. The SEM images of nanozeolite $\mathrm{Y}$ and produced granules are illustrated in Fig. 3 and 4. Fig. 5 shows the SEM image of the surfactant modified granulated nanozeolite Y. The BET surface area of nanozeolite $\mathrm{Y}$ and granulated nanozeolite $\mathrm{Y}$ is 705.6 and $370.8 \mathrm{~m}^{2} / \mathrm{g}$, respectively.

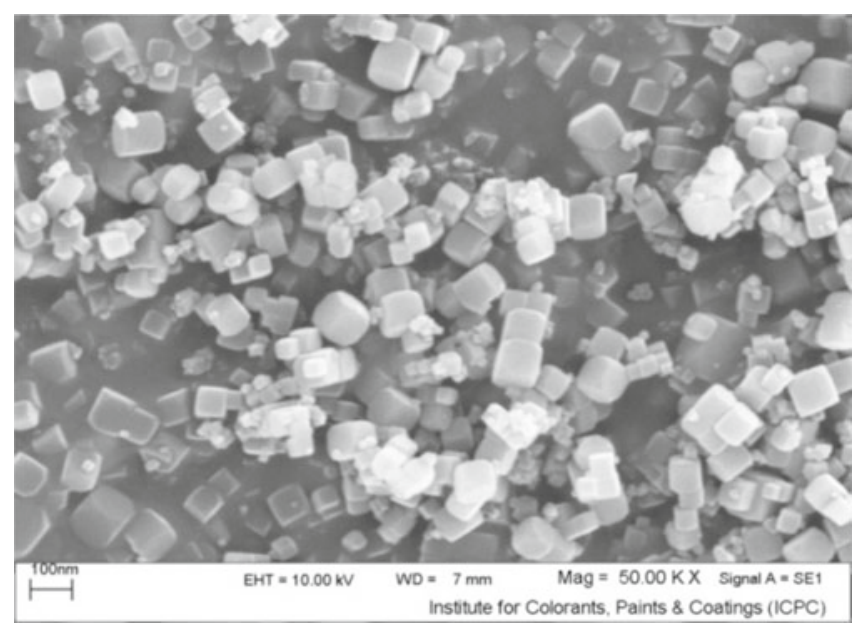

Figure 3. SEM image of nanozeolite $\mathrm{Y}$

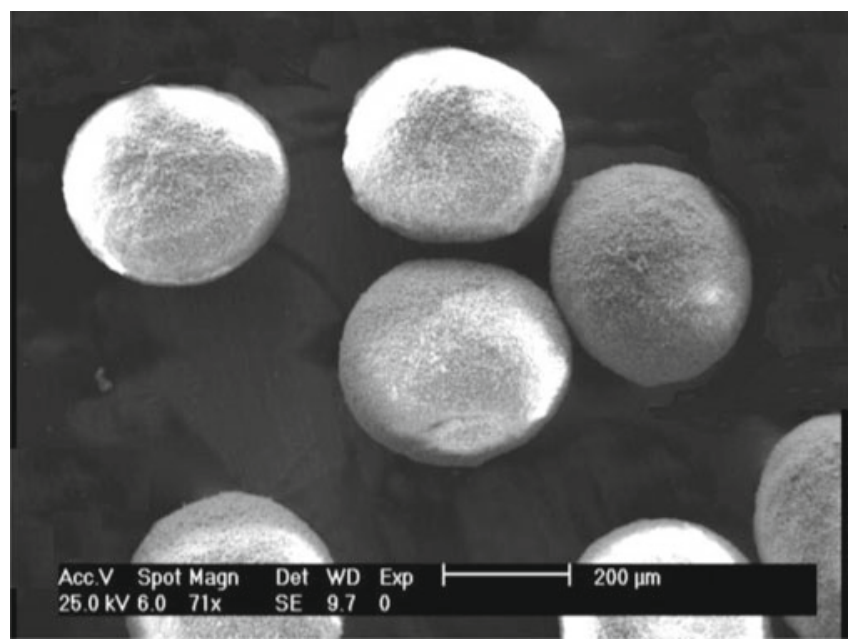

Figure 4. SEM image of granulated nanozeolite Y

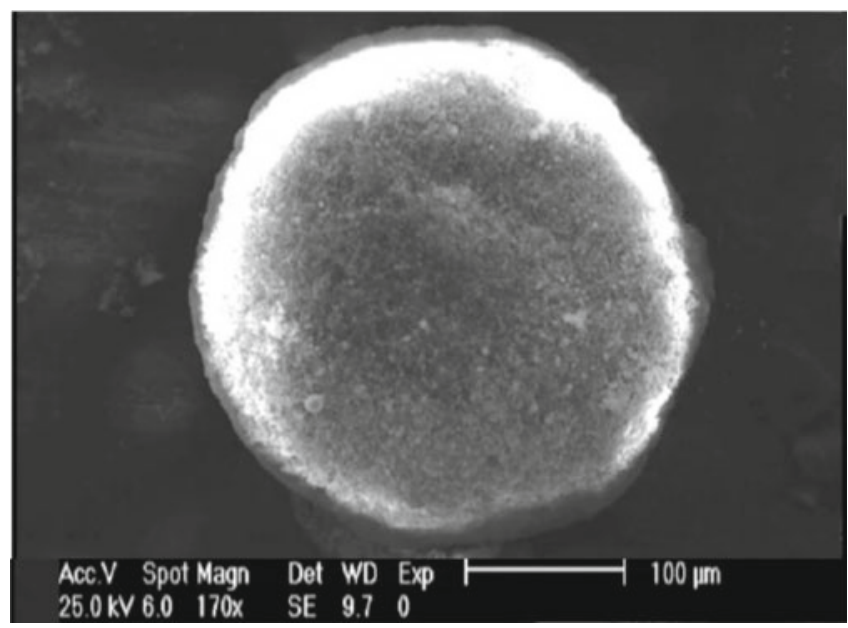

Figure 5. SEM image of surfactant modified granulated nanozeolite Y

\section{Adsorption Capacity}

The results of MTBE adsorption capacity with two types of adsorbent (GMN-Y\#1 and GMN-Y\#2) are illustrated in Fig. 6. The adsorbents dry weight was $0.5 \mathrm{~g}$. 


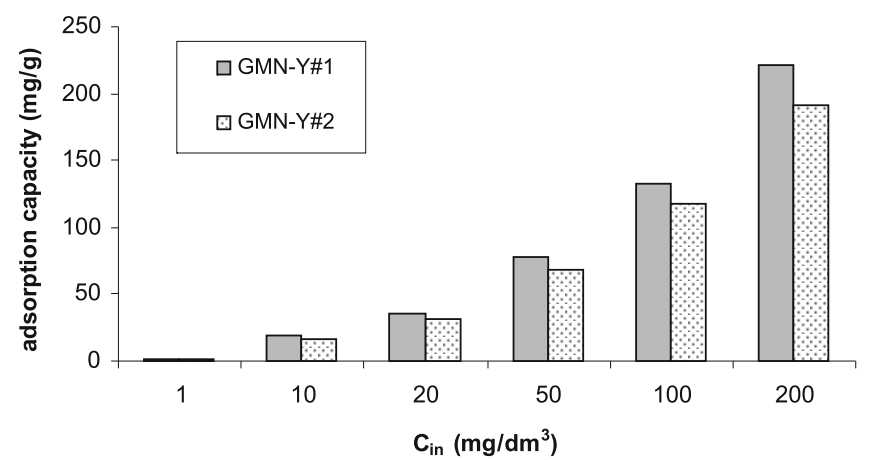

Figure 6. Adsorption capacity of MTBE by GMN-Y\#1 and GMN-Y\#2

According to the obtained results (Fig. 6), it is obvious that GMN-Y\#1 is more effective than GMN-Y\#2 in any concentration. On the other hand, the results showed that the adsorption capacity of MTBE was highly concentration dependent. In different concentrations of MTBE, the parameter of adsorption capacity increased with the MTBE concentration. The molecules of MTBE at higher concentrations play as a driving force and overcome the mass transfer resistance between the aqueous and solid phases. Therefore, the maximum adsorption capacity of GMN- Y took place at higher concentrations of MTBE.

\section{Adsorption Isotherms}

Isotherms help to determine the maximum adsorptive capacity of the material and to evaluate the mechanism of performance of the adsorption system. In addition, it allows an evaluation how an adsorption system can be improved. Therefore, an Isotherm study is essential in improving the use of adsorbent. Several isotherm equations have been published in the literature. The Langmuir, Freundlich and Temkin models are the most widely employed isotherms for modeling the adsorption in single-solute systems. In this study, seven most frequently employed isotherm models, namely, Langmuir ${ }^{1-4}$, Fruendlich, Temkin and Dubinin-Radushkevich (D-R) were used for the analysis of the obtained data. The linear forms and Parameters of seven used isotherms are listed in Table 1.

Table 1. Isotherms and their linear expressions

\begin{tabular}{|c|c|c|c|c|}
\hline Isotherm & Linear equation & Plot & Parameters & Reference \\
\hline Langmuir 1 & $\frac{C_{e}}{q_{e}}=\left(\frac{1}{K_{L} q_{m}}\right)+\left(\frac{1}{q_{m}}\right) C_{e}$ & $C_{e} / q_{e}$ vs. $C_{e}$ & $\begin{array}{c}\mathrm{q}_{\mathrm{m}}=1 / \text { slope } \\
\mathrm{K}_{\mathrm{L}}=1 /\left(\text { intercept } \times \mathrm{q}_{\mathrm{m}}\right)\end{array}$ & 16 \\
\hline Langmuir 2 & $\frac{1}{q_{e}}=\frac{1}{Q_{m}}+\left(\frac{1}{K_{L} Q_{m}}\right) \frac{1}{C_{e}}$ & $1 / C_{e}$ vs. $1 / q_{e}$ & $\begin{array}{c}\mathrm{q}_{\mathrm{m}}=1 / \text { intercept } \\
\mathrm{K}_{\mathrm{L}}=\text { intercept/slope }\end{array}$ & 16 \\
\hline Langmuir 3 & $q_{e}=Q_{m}-\left(\frac{1}{K_{L}}\right) \frac{q_{e}}{C_{e}}$ & $\mathrm{q}_{\mathrm{e}} / C_{\mathrm{e}}$ vs. $\mathrm{q}_{\mathrm{e}}$ & $\begin{array}{l}\mathrm{q}_{\mathrm{m}}=\text { intercept } \\
\mathrm{K}_{\mathrm{L}}=1 / \text { slope }\end{array}$ & 16 \\
\hline Langmuir 4 & $\frac{q_{e}}{C_{e}}=K_{L} Q_{m}-K_{L} q_{e}$ & $q_{e}$ vs. $q_{e} / C_{e}$ & $\begin{array}{c}\mathrm{K}_{\mathrm{L}}=\text { slope, } \\
\mathrm{q}_{\mathrm{m}}=\text { intercept/slope }\end{array}$ & 16 \\
\hline Freundlich & $\log (q e)=\log \left(K_{f}\right)+(1 / n) \log \left(C_{e}\right)$ & $\begin{array}{l}\log \left(q_{e}\right) \text { vs. } \\
\log \left(C_{e}\right)\end{array}$ & $\begin{array}{c}K_{f}=\exp (\text { intercept }) \\
1 / n=\text { slope }\end{array}$ & 17 \\
\hline Temkin & $q_{e}=B_{T} \ln A_{T}+B_{T} \ln C e$ & $q_{e}$ vs. $\ln \left(C_{e}\right)$ & $\begin{array}{c}\mathrm{B}_{\mathrm{T}}=\text { slope } \\
\ln \mathrm{A}_{\mathrm{T}}=\text { intercept/ } \mathrm{B}_{\mathrm{T}}\end{array}$ & 18 \\
\hline $\begin{array}{l}\text { Dubinin- } \\
\text { Radushkevich }\end{array}$ & $\ln q_{e}=\ln Q_{m}-\left(\frac{R T}{E}\right)^{2}\left[\ln \left(\frac{C_{S}}{C_{e}}\right)\right]^{2}$ & $\begin{array}{l}\ln \mathrm{q}_{\mathrm{e}} \text { vs. } \\
{\left[\ln \left(\mathrm{C}_{\mathrm{s}} / \mathrm{C}_{\mathrm{e}}\right)\right]^{2}}\end{array}$ & $\begin{array}{c}E=\text { slope } \\
q_{m}=\text { intercept }\end{array}$ & 19 \\
\hline
\end{tabular}

\section{Langmuir Model}

The Langmuir isotherm assumes that adsorption takes places at specific homogenous surfaces of the adsorbent. Moreover, the Langmuir isotherm represents a single coating layer of the adsorbate on the adsorbent surface ${ }^{\mathbf{2 0}}$. The Langmuir isotherm can be linearized as four differconstants in the linear equations can be calculated from the slope and intercept of the plots between the mentioned expressions (table 1). The obtained values of the Langmuir isotherm parameters are given in Table 2. The results show that the Langmuir correlation coefficients $\left(\mathrm{R}^{2}\right)$ are in the range of 0.914 to 0.999 . And the values of $\mathrm{R}^{2}$ were in the order of Langmuir $2>$ Langmuir 1 $>$ Langmuir 3 and Langmuir 4. Therefore $\mathrm{R}^{2}$ values indicate that Langmuir 2 fits all of the experimental data better than other Langmuir isotherms (Fig. 7). It has been found that GMN-Y\#1 shows better adsorption capacity $(\mathrm{mg} / \mathrm{g})$ than GMN-Y\#2. As calculated by the Langmuir 2 model, the maximum adsorption capacity for GMN-Y\#1 and GMN-Y\#2 is 333.33 and 142.8 ( $\mathrm{mg} / \mathrm{g})$, respectively. Langmuir isotherm can be obtained from a dimensionless constant called equilibrium factor $\left(R_{L}\right)$. Which $R_{L}$ can be defined by following equation:

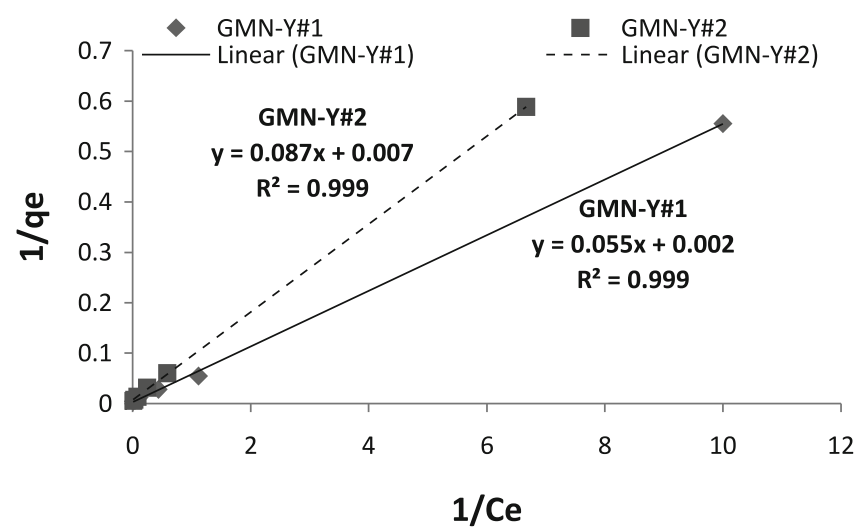

Figure 7. Application of Langmuir 2 model to MTBE adsorption onto GMN-Y\#1 and GMN- Y\#2 ent types of isotherms as shown in table 1. The isotherm

On the other hand, the essential characteristic of 
Table 2. Isotherm parameters obtained from the four linear forms of Langmuir model

\begin{tabular}{|c|c|c|c|c|c|c|c|c|c|c|}
\hline \multirow{4}{*}{$\begin{array}{l}\text { Isotherm } \\
\text { model }\end{array}$} & \multirow{4}{*}{ adsorbent } & \multicolumn{9}{|c|}{ Langmuir isotherm parameters } \\
\hline & & \multirow{3}{*}{$\begin{array}{c}\mathrm{q}_{\mathrm{m}} \\
(\mathrm{mg} / \mathrm{g})\end{array}$} & \multirow{3}{*}{$\begin{array}{c}\mathrm{K}_{\mathrm{L}} \times 10^{3} \\
\left(\mathrm{dm}^{3} / \mathrm{mg}\right)\end{array}$} & \multirow{3}{*}{$\mathrm{R}^{2}$} & \multicolumn{6}{|c|}{$\mathrm{R}_{\mathrm{L}}$} \\
\hline & & & & & \multicolumn{6}{|c|}{ MTBE initial concentration $\left(\mathrm{mg} / \mathrm{dm}^{3}\right)$} \\
\hline & & & & & 1 & 10 & 20 & 50 & 100 & 200 \\
\hline \multirow{2}{*}{ Langmuir 1} & GMN-Y\#1 & 250.0 & 0.05 & 0.996 & 0.952 & 0.666 & 0.500 & 0.285 & 0.166 & 0.091 \\
\hline & GMN-Y\#2 & 99.19 & 0.04 & 0.994 & 0.961 & 0.714 & 0.555 & 0.333 & 0.200 & 0.111 \\
\hline \multirow{2}{*}{ Langmuir 2} & GMN-Y\#1 & 333.33 & 0.036 & 0.999 & 0.965 & 0.735 & 0.581 & 0.357 & 0.217 & 0.122 \\
\hline & GMN-Y\#2 & 142.8 & 0.08 & 0.999 & 0.926 & 0.555 & 0.384 & 0.200 & 0.111 & 0.058 \\
\hline \multirow{2}{*}{ Langmuir 3} & GMN-Y\#1 & 18.55 & 12.65 & 0.914 & 0.073 & 0.007 & 0.007 & 0.004 & 0.0008 & 0.0004 \\
\hline & GMN-Y\#2 & 10.23 & 21.27 & 0.939 & 0.045 & 0.004 & 0.002 & 0.001 & 0.0004 & 0.0002 \\
\hline \multirow{2}{*}{ Langmuir 4} & GMN-Y\#1 & 19.17 & 11.58 & 0.914 & 0.080 & 0.008 & 0.004 & 0.002 & 0.0008 & 0.0004 \\
\hline & GMN-Y\#2 & 10.45 & 19.69 & 0.939 & 0.048 & 0.005 & 0.002 & 0.001 & 0.0005 & 0.0003 \\
\hline
\end{tabular}

$$
R_{L}=\frac{1}{1+\left(K_{L} C_{i}\right)}
$$

Where:

$\mathrm{C}_{i}$ is the initial concentration of adsorbate $\left(\mathrm{mg} / \mathrm{dm}^{3}\right)$ and $K_{L}$ is the Langmuir constant $\left(\mathrm{dm}^{3} / \mathrm{mg}\right)$. The $R_{L}$ value indicates the isotherm shape. The $R_{L}$ value in the range from zero to one, indicates a favorable adsorption condition $^{21}$. As mentioned in Table 2, the equilibrium factor values for the Langmuir isotherm models are in the range of 0.002 to 0.965 . The $R_{L}$ values indicate that adsorption processes of MTBE by GMN-Y are favorable. Similar results were obtained for MTBE and even the BTEX compounds uptake from water using surfactant modified natural zeolites in our previously works ${ }^{13,14}$.

\section{Freundlich Model}

Freundlich model is an empirical method that is suitable for the description of an adsorption process in heterogeneous systems. On the other hand, the Freundlich model represents a multilayer adsorption on the heterogeneous surface. The Freundlich isotherm constants $\left(1 / \mathrm{n}\right.$ and $\left.\mathrm{K}_{\mathrm{F}}\right)$ can be calculated by plotting $\log \left(\mathrm{q}_{\mathrm{e}}\right)$ versus $\log \left(\mathrm{C}_{\mathrm{e}}\right)$ (Table 1). Parameter $1 / \mathrm{n}$ is the heterogeneity factor that shows the adorability of the adsorption process. KF $\left(\mathrm{mg} / \mathrm{g}\left(\mathrm{dm}^{3} / \mathrm{mg}\right) 1 / \mathrm{n}\right)$ is the Freundlich constant or adsorption coefficient ${ }^{15}$. For other materials it was found that the Freundlich kinetic is the best model of describing the kinetic data for MTBE removal from water ${ }^{22}$. The parameters of the Freundlich isotherm are presented in Table 3. As the results show, the Freundlich correlation coefficients $\left(\mathrm{R}^{2}\right)$ for adsorption of MTBE by GMN-Y\#1 and GMN-Y\#2 are 0.959 and 0.976, respectively. But in comparison with the Langmuir model, the Freundlich isotherm model is not fitted very well by this study's data. It means that, because the $\mathrm{R}^{2}$ obtained from the Langmuir isotherm is better than the Freundlich isotherm, the absorption process of MTBE on GMN-Y is chemical and makes a monolayer of MTBE molecules on adsorbents surface. Moreover, if the value of $1 / n$ become below one, the Freundlich model reduces to the normal Langmuir isotherm ${ }^{23}$. Because $1 / \mathrm{n}$ values of this study are less than one (table 3 ), we can conclude that the Langmuir model is a stronger isotherm than the Freundlich model.

\section{Temkin Model}

The Temkin isotherm model express that the adsorption heat of all the molecules in the layer declines linearly with coverage due to adsorbent-adsorbate interactions ${ }^{18}$. The Temkin isotherm parameters $\left(B_{T}\right.$ and $\left.\mathrm{A}_{\mathrm{T}}\right)$ can be calculated by plotting $\mathrm{q}_{\mathrm{e}}$ versus $\ln \left(\mathrm{C}_{\mathrm{e}}\right)$ (Table 1). Parameter $B_{T}(\mathrm{~J} / \mathrm{mol})$ is the temkin isotherm constant related to the heat of sorption and $A_{T}\left(\mathrm{dm}^{3}\right)$ $\mathrm{mg}$ ) is the equilibrium binding constant, corresponding to the maximum binding energy. The results of this model are represented in table 3 . According to the results, the correlation coefficients of the Temkin isotherm model are lower than the Langmuir and even the Freundlich models. Therefore, the adsorption process of MTBE on GMN-Y does not fit the Temkin Model.

\section{Dubinin-Radushkevich Model}

Another isotherm equation that was also used to test the experimental data was the Dubinin-Radushkevich (D-R) equation. It does not assume a constant sorption potential or a homogeneous surface ${ }^{24}$. The Dubinin-Radushkevich parameters ( $\mathrm{E}$ and qs) can be calculated by plotting ln qe versus $[\ln (\mathrm{Cs} / \mathrm{Ce})]^{2}$ (Table 1$)$. Parameter $\mathrm{E}(\mathrm{KJ} / \mathrm{mol})$ is the mean free energy of sorption per adsorbate molecule and $\mathrm{q}_{\mathrm{s}}(\mathrm{mg} / \mathrm{g})$ is the maximum adsorption capacity. Depending on the obtained results from the linear regression of Dubinin-Radushkevich isotherm (table 3), the correlation coefficients of this method are even less than the other above discussed isotherm models. Therefore, this method does not fit the experimental data.

\section{Adsorption Kinetics}

Prediction of the contamination removal rate from aqueous solutions is very important and interesting in order to design an adsorption treatment plant. Kinetic

Table 3. Isotherm parameters obtained from Freundlich, Temkin and Dubinin-Radushkevich models

\begin{tabular}{|c|c|c|c|c|c|c|c|c|c|}
\hline \multirow{3}{*}{ adsorbent } & \multicolumn{9}{|c|}{ Isotherm model } \\
\hline & \multicolumn{3}{|c|}{ Freundlich } & \multicolumn{3}{|c|}{ Temkin } & \multicolumn{3}{|c|}{ Dubinin-Radushkevich } \\
\hline & $\begin{array}{c}K_{F} \\
\left(\mathrm{dm}^{3} / g\right)\end{array}$ & $1 / n$ & $\mathrm{R}^{2}$ & $\begin{array}{c}\mathrm{B}_{\mathrm{T}} \\
(\mathrm{J} / \mathrm{mol})\end{array}$ & $\begin{array}{c}A_{T} \\
\left(\mathrm{dm}^{3} / \mathrm{mg}\right)\end{array}$ & $\mathrm{R}^{2}$ & $\begin{array}{c}\mathrm{q}_{\mathrm{m}} \\
(\mathrm{mg} / \mathrm{g})\end{array}$ & $\begin{array}{c}\mathrm{E} \\
(\mathrm{KJ} / \mathrm{mol})\end{array}$ & $\mathrm{R}^{2}$ \\
\hline GMN-Y\#1 & 3.183 & 0.704 & 0.959 & 32.67 & 3.337 & 0.868 & 6.183 & 0.715 & 0.690 \\
\hline GMN-Y\#2 & 2.622 & 0.730 & 0.976 & 28.96 & 2.137 & 0.841 & 6.295 & 1.312 & 0.858 \\
\hline
\end{tabular}


Table 4. Kinetics and their linear expressions

\begin{tabular}{|c|c|c|c|c|}
\hline Kinetic model & Linear equation & Plot & Parameters & Reference \\
\hline $\begin{array}{l}\text { Pseudo } \\
\text { first-order }\end{array}$ & $\log \left(q_{e}-q_{t}\right)=\log \left(q_{e}\right)-\frac{k_{1}}{2.303} t$ & $\begin{array}{l}\log \left(q_{e}-q_{t}\right) \\
\text { vs. } t\end{array}$ & $\begin{array}{c}\mathrm{k}_{1}=\text { slope } \\
\mathrm{q}_{\mathrm{e}}=\text { intercept }\end{array}$ & 24,25 \\
\hline $\begin{array}{l}\text { Pseudo second- } \\
\text { order }\end{array}$ & $\frac{t}{q_{t}}=\left(\frac{1}{k_{2} q_{e}^{2}}\right)+\left(\frac{1}{q_{e}}\right) t$ & $t / q_{t}$ vs. $t$ & $\begin{array}{c}1 / q_{e}=\text { Slope } \\
1 /\left(k_{2} q_{e}^{2}\right)=\text { Intercept }\end{array}$ & 25,26 \\
\hline Elovich & $q_{e}=\left(\frac{1}{\beta}\right) \ln (\alpha \beta)+\left(\frac{1}{\beta}\right) \ln t$ & $\mathrm{q}_{\mathrm{t}} \mathrm{vs} \cdot \ln (\mathrm{t})$ & $\begin{array}{c}1 / \beta=\text { Slope } \\
1 / \beta \times \ln (\alpha \beta)=\text { Intercept }\end{array}$ & 24 \\
\hline $\begin{array}{l}\text { Intraparticle } \\
\text { Diffusion }\end{array}$ & $q_{t}=K_{d i f} t^{0.5}+C$ & $q_{t}$ vs. ?t & $\begin{array}{c}\mathrm{C}=\text { Intercept } \\
\mathrm{K}_{\text {dif }}=\text { Slope }\end{array}$ & 25 \\
\hline
\end{tabular}

\begin{tabular}{|c|c|c|c|c|c|c|c|}
\hline \multirow{2}{*}{ Adsorbent } & \multirow{2}{*}{ Initial MTBE $\left(\mathrm{mg} / \mathrm{dm}^{3}\right)$} & \multicolumn{3}{|c|}{ Pseudo first-order } & \multicolumn{3}{c|}{ Pseudo second-order } \\
\cline { 2 - 7 } & & $\mathrm{q}_{\mathrm{e}}(\mathrm{mg} / \mathrm{g})$ & $\mathrm{K}_{1}(1 / \mathrm{min})$ & $\mathrm{R}^{2}$ & $\mathrm{q}_{\mathrm{e}}(\mathrm{mg} / \mathrm{g})$ & $\mathrm{K}_{2}(\mathrm{~g} / \mathrm{mg} \cdot \mathrm{min})$ & $\mathrm{R}^{2}$ \\
\hline & 50 & 2.449 & 0.001 & 0.905 & 90.90 & 0.005 & 0.997 \\
\hline GMN-Y\#1 & 100 & 2.862 & 0.001 & 0.828 & 142.85 & 0.006 & 0.999 \\
\hline & 200 & 3.009 & 0.002 & 0.903 & 250 & 0.005 & 0.998 \\
\hline GMN-Y\#2 & 50 & 2.535 & 0.002 & 0.909 & 76.923 & 0.005 & 0.999 \\
\hline & 100 & 2.928 & 0.003 & 0.756 & 125 & 0.005 & 0.997 \\
\hline
\end{tabular}

Table 5. Comparison of pseudo first- and second-order kinetics parameters for different GMN-Y and initial concentrations

studies are useful for the prediction of adsorption reaction rate, modeling and designing the processes. Therefore, four most commonly used kinetic methods: pseudo firstorder; pseudo second-order; Intraparticle Diffusion and Elovich were used to represent the experimental data. The linear forms and Parameters of four employed kinetic methods are listed in Table 4. The effect of contact time was carried out by ranging from 1 to 24 hours in order to perform the kinetic study. And three different initial concentrations of MTBE used, which were 50, 100 and $200 \mathrm{mg} / \mathrm{dm}^{3}$. The solution $\mathrm{pH}$ was kept constant at 7.1 during experiments.

\section{Pseudo First-Order Model}

Pseudo first-order kinetics is the one of the earliest methods of describing the adsorption rate based on the adsorption capacity. The Pseudo first-order parameters $\left(\mathrm{k}_{1}\right.$ and $\left.\mathrm{q}_{\mathrm{e}}\right)$ can be calculated by plotting $\log \left(\mathrm{q}_{\mathrm{e}}-\mathrm{q}_{\mathrm{t}}\right)$ versus $t$, as shown in table 4 . Parameter $k_{1}(1 / \mathrm{min})$ is the first-order adsorption rate constant and $\mathrm{q}_{\mathrm{e}}(\mathrm{mg} / \mathrm{g})$ is the maximum adsorption capacity at equilibrium. Table 5 shows the Pseudo first-order kinetic parameters corresponding to MTBE removal by granulated modified nanozeolites $\mathrm{Y}$. The obtained values of $\mathrm{R}^{2}$ for the Pseudo first-order kinetics (Table 5) show that this model was not fit to the experimental data.

\section{Pseudo Second-Order Model}

The pseudo second- order method was explained by $\mathrm{Ho}^{27}$ and its adsorption mechanism is relative to chemical adsorption. The characteristics of Pseudo second-order kinetic are mentioned in Table 4 and the results are summarized in Table 5. According to the results, the correlation coefficients for both of adsorbents were greater than 0.997 (Fig. 8 and Fig. 9). Therefore, the second-order equation provided a good fitting to the experimented data in contrast to the pseudo first-order model.

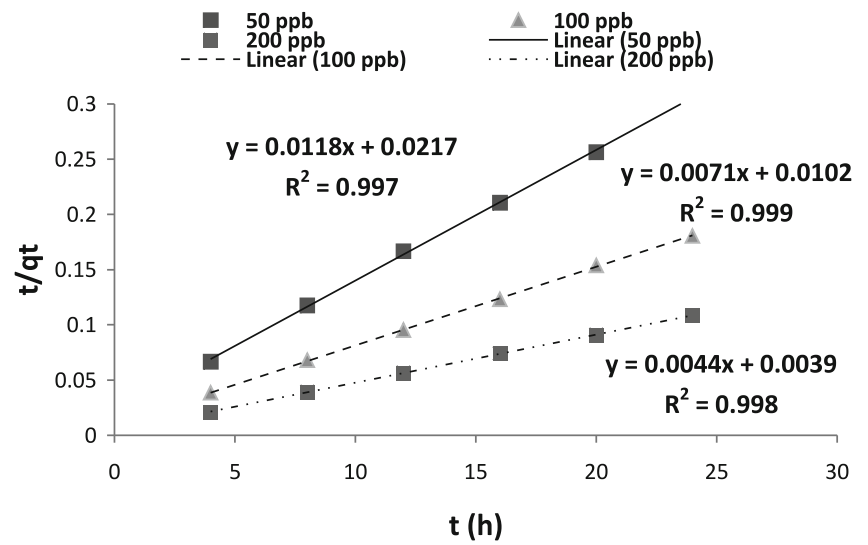

Figure 8. Pseudo second-order adsorption kinetics of MTBE on GMN-Y\#1

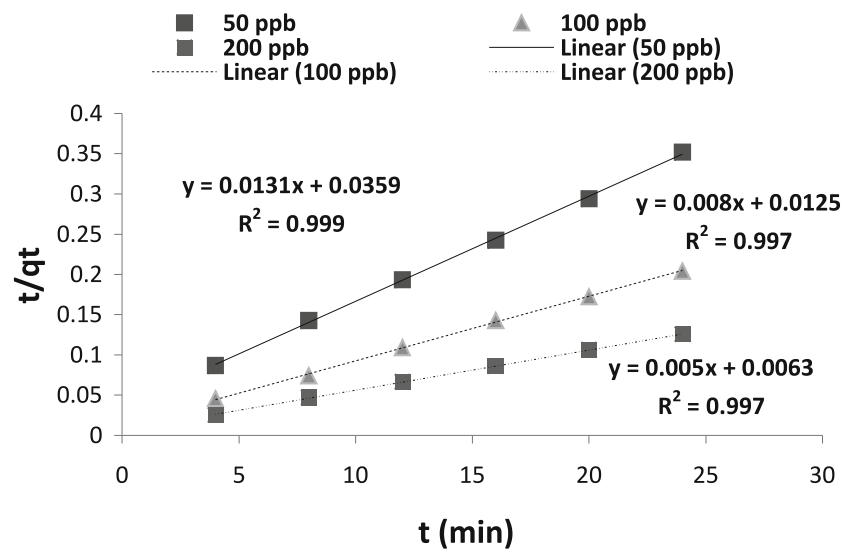

Figure 9. Pseudo second-order adsorption kinetics of MTBE on GMN-Y\#2

\section{Elovich Model}

Another rate equation that also used to test the experimental data was the Elovich Model, which is based on the adsorption capacity. The Elovich model is useful to describe adsorption processes without the desorption of adsorbate ${ }^{28}$. The constants of the Elovich kinetic (A and B) can be obtained from the intercept and the slope of the straight line (Table 4 ). The $\mathrm{R}^{2}$ values obtained 
Table 6. The parameters of Elovich and Intraparticle Diffusion kinetic methods using different GMN-Y and initial concentrations

\begin{tabular}{|c|c|c|c|c|c|c|c|}
\hline \multirow[b]{2}{*}{ Adsorbent } & \multirow{2}{*}{$\begin{array}{c}\text { Initial MTBE } \\
\left(\mathrm{mg} / \mathrm{dm}^{3}\right)\end{array}$} & \multicolumn{3}{|c|}{ Elovich } & \multicolumn{3}{|c|}{ Intraparticle Diffusion } \\
\hline & & $\begin{array}{c}\alpha \\
(\mathrm{mg} / \mathrm{g} \cdot \mathrm{min})\end{array}$ & $\begin{array}{c}B \\
(\mathrm{~g} / \mathrm{mg})\end{array}$ & $\mathrm{R}^{2}$ & $\begin{array}{c}\mathrm{C} \\
(\mathrm{mg} / \mathrm{g})\end{array}$ & $\begin{array}{c}\mathrm{K}_{\mathrm{dif}} \\
\left(\mathrm{mg} / \mathrm{g} \cdot \mathrm{min}^{0.5}\right)\end{array}$ & $\mathrm{R}^{2}$ \\
\hline & 50 & 6.604 & 0.093 & 0.991 & 53.07 & 4.074 & 0.882 \\
\hline \multirow[t]{3}{*}{ GMN-Y\#1 } & 100 & 7.957 & 0.062 & 0.965 & 95.77 & 5.943 & 0.808 \\
\hline & 200 & 12.81 & 0.059 & 0.994 & 181.0 & 6.404 & 0.890 \\
\hline & 50 & 4.783 & 0.077 & 0.982 & 38.37 & 4.585 & 0.846 \\
\hline \multirow[t]{2}{*}{ GMN-Y\#2 } & 100 & 7.336 & 0.065 & 0.910 & 82.09 & 5.683 & 0.760 \\
\hline & 200 & 9.917 & 0.053 & 0.991 & 145.0 & 7.241 & 0.888 \\
\hline
\end{tabular}

by the Elovich model (Table 6) were higher than that obtained from the first-order kinetics. But the $\mathrm{R}^{2}$ values of the Elovich model are comparable to that obtained from the pseudo second-order model.

\section{Intraparticle Diffusion Model}

The Weber and Morris sorption kinetic model that is the most widely applied intraparticle diffusion equation $^{25}$, was employed to analyzing the sorption kinetics. According to the $\mathrm{R}^{2}$ values (Table 6), experimental data are not following the Intraparticle Diffusion kinetics.

\section{CONCLUSION}

Granulated modified nanozeolite $\mathrm{Y}$ was used for removal of MTBE. In order to investigate the effect of adsorbents modification, granulated nanozeolites were modified by two cationic surfactants namely HDTMA-Cl and CPB. HDTMA-Cl modified granulated nanozeolite showed a better adsorption capacity for MTBE than CPB modified samples. Isotherm Studies were performed at initial concentrations with the range of of 1 to $200 \mathrm{mg} /$ $\mathrm{dm}^{3}$. the adsorption capacity $(\mathrm{mg} / \mathrm{g})$ of GMN- Y increased with the initial concentration of MTBE solutions. It means that, maximum adsorption capacity of GMN- Y took place at higher concentrations of MTBE, which the Langmuir parameters can prove.

The adsorption isotherms of MTBE on GMN-Y were well described by the Langmuir 2 adsorption equation. The RL values obtained from the Langmuir isotherms expressed that adsorption processes of MTBE on GMN$\mathrm{Y}$ were favorable. The adsorption kinetics for MTBE removal from water followed the pseudo-second-order kinetic method. The obtained data from the Langmuir isotherm and the pseudo-second-order kinetic models represent that the absorption process of MTBE on GMN-Y is chemical and makes a monolayer of MTBE molecules on the adsorbents surface. The monolayer adsorption capacity by GMN-Y\#1and GMN-Y\#2 was 333.33 and $142.8(\mathrm{mg} / \mathrm{g})$ respectively, which is comparable with the adsorption capacity of other sorbents previously studied in other works.

\section{NOMENCLATURE}

$\mathrm{A}_{\mathrm{T}} \quad$ Temkin constant $\left(\mathrm{dm}^{3} / \mathrm{g}\right)$

$B_{T} \quad$ constant related to heat of adsorption $\left(\mathrm{mg} / \mathrm{dm}^{3}\right)$

$\mathrm{C}_{\mathrm{e}} \quad$ equilibrium concentration in solution $\left(\mathrm{mg} / \mathrm{dm}^{3}\right)$

$\mathrm{C}_{\mathrm{s}} \quad$ saturation concentration in solution $\left(\mathrm{mmol} / \mathrm{dm}^{3}\right)$

$\mathrm{C}_{\mathrm{t}}$ equilibrium concentration in solution at time $\mathrm{t}$ $\left(\mathrm{mg} / \mathrm{dm}^{3}\right)$ $\mathrm{k}_{1} \quad$ pseudo first-order rate constant $(1 / \mathrm{min})$

$\mathrm{k}_{2} \quad$ pseudo second-order rate constant $(\mathrm{g} / \mathrm{mg} \min )$

$\mathrm{K}_{\text {dif }} \quad$ intraparticle diffusion rate constant $\left(\mathrm{mg} / \mathrm{g} \mathrm{min}^{0.5}\right)$

$\mathrm{K}_{\mathrm{f}} \quad$ Freundlich isotherm constants $\left(\mathrm{dm}^{3} / \mathrm{g}\right)$

$\mathrm{K}_{\mathrm{L}} \quad$ Langmuir isotherm constants $\left(\mathrm{dm}^{3} / \mathrm{mg}\right)$

$\mathrm{n} \quad$ adsorption intensity

$\mathrm{q}_{\mathrm{e}} \quad$ equilibrium adsorbent concentration on adsorbent $(\mathrm{mg} / \mathrm{g})$

$\mathrm{q}_{\mathrm{m}} \quad$ maximum monolayer capacity $(\mathrm{mg} / \mathrm{g})$

$\mathrm{q}_{\mathrm{t}} \quad$ adsorbed metal concentration at time $\mathrm{t}(\mathrm{mg} / \mathrm{g})$

$\mathrm{R}^{2} \quad$ correlation coefficients

$\mathrm{R}_{\mathrm{L}} \quad$ Langmuir equilibrium factor

$\alpha \quad$ initial adsorption rate ( $\mathrm{mg} / \mathrm{g} \cdot \mathrm{min})$

$\beta \quad$ desorption constant $(\mathrm{g} / \mathrm{mg})$

\section{ACKNOWLEDGMENT}

The authors acknowledge financial support provided by Deputy of Research, Tehran University of Medical Sciences. The authors also wish to acknowledge the Pars Oil and Gas Company for financial support of this study.

\section{LITERATURE CITED}

1. Mortazavi, S., Nikpey, A., Rezaee, A., Asilian, H., Khavanin, A. \& Kazemian, H. (2005). Methl Tert-Butyl Ether (MTBE) degradiation by a microbial consortium. Am. J. Environ Sci., 1, 69-73.

2. Mackay, D., Shiu, W. \& Ma, K. (1993). Illustrated handbook of physical-chemical properties and environmental fate for organic chemicals-volatile organic chemicals, Chelsea, MI: Lewis.

3. Schmidt, T.C., Schirmer, M., Weiss, H. \& Haderlein, S. B. (2004). Microbial degradation of methyl tert-butyl ether and tertbutyl alcohol in the subsurface. J. Contam. Hydrol. 70, 173-203.

4. Klinger, J., Stieler, C., Sacher, F. \& Branch, H.J. (2004). MTBE (methyl tertiary-butyl ether) in groundwaters: monitoring results from Germany. J. Environ. Monit. 4, 276-279.

5. WHO (2005). Methyl tertiary-Butyl Ether (MTBE) in Drinking-water. Background document for development of WHO Guidelines for Drinking-water Quality. SDE/WSH/05.08/122.

6. Quinlivan, P.A., Li, L. \& Knappe, D.R.U. (2005). Effects of activated carbon characteristics on the simultaneous adsorption of aqueous organic micropollutants and natural organic matter. Water Res. 39, 1663-1673. doi:10.1016/j.watres.2005.01.029

7. Malek, N.N. (2007). Surfactant modified zeolite Y as a sorbent for some chromium and arsenic species in water. Faculty of Science. Universiti Teknologi Malaysia.

8. Tashauoei, H., Attar, M.M., Amin, M.M., Kamali, M., Nikaeen, M. \& Dastjerdi, M.V. (2010). Removal of cadmium and humic acid from aqueous solutions using surface modified nanozeolite A. Int. J. Environ. Sci. Technol. 7, 497-508.

9. Liu, Z. M., Becker, T. \& Neufeld, R.J. (2005). Spherical 
Alginate Granules Formulated for Quick-Release Active Subtilisin. Biotechnol. Prog. 21, 568-574.

10. Charkhi, A., Kazemian, H. \& Kazemeini, M. (2010). Optimized experimental design for natural Clinoptilolite zeolite ball milling to produce nano powders. Powder Technol. 203, 389-396. doi:10.1016/j.powtec.2010.05.034.

11. Kazemeinia, M., Charkhi, A., Kazemian, H. \& AHMADI, S.J. (2010). Granulation of nano zeolites utilizing sodium alginate as an external template. Iran International Zeolite Conference 2th IIZC. Tehran.

12. Zhang, P., Tao, X., Li, Z. \& Bowman, R.S. (2002). Enhanced perchloroethylene reduction in column systems using surfactant-modified zeolite/zero-valent iron pellets. Environ. Sci. Technol. 36, 3597-3603.

13. Torabian, A., Kazemian, H., Seifi, L., Bidhendi, G.N. \& Ghadiri, S.K. (2010). Removal of Petroleum Aromatic Hydrocarbons by Surfactant-Modified Natural Zeolite. CLEAN - Soil, Air, Water, 38, 77-83.

14. Ghadiri, S.K., Nabizade, R., Mahvi, A.H., Kazemian, H., Mesdaghinia, A.R. \& Nazmara, S. (2010). Methyl Tert Butyl Ether Adsorption on Surfactant Modified Natural Zeolites. Iran. J. Environ. Health. Sci. Eng. 7, 235-246.

15. Seifi, L., Torabian, A., Kazemian, H., Bidhendi, G.N., Azimi, A.A., Farhadi, F. \& Charkhi, A. (2011). Kinetic Study of BTEX Removal Using Granulated Surfactant Modified Natural Zeolites Nanoparticles. Water Air Soil Poll. 219, 443-457 DOI 10.1007/s11270-010-0719-z.

16. Ho, Y.-S. (2006). Isotherms for the Sorption of Lead onto Peat: Comparison of Linear and Non-Linear Methods. Pol. J. Environ. Stud. 15, 81-86.

17. Freundlich, H.M.F. (1906). Uber die adsorption in losungen. J. Phys. Chem. 57, 358-470.

18. Tempkin, M.J. \& Pyzhev, V. (1940). Kinetics of ammonia synthesis on promoted iron catalysts. Acta Physicochim, 12, 217-256.

19. Rengaraj, S., Kim, Y., Joo, C.K., Choi, K. \& Yi, J. (2004). Batch adsorptive removal of copper ions in aqueous solutions by ion exchange resins: $1200 \mathrm{H}$ and IRN97H. Korean J. Chem. Eng. 21, 187-194.

20. Langmuir, I. (1916). The constitution and fundamental properties of solids and liquids. J. Am. Chem. Soc. 38, 2221-2295.

21. Acemioglu, B. (2004). Removal of Fe ion from aqueous solution by calabrian pine bark waste. Bioresource Technol. 93, 99-102. doi:10.1016/j.biortech.2003.10.010

22. Hung, H.W. \& Lin, T.F. (2006). Adsorption of MTBE from contaminated water by carbonaceous resins and mordenite zeolite. J. Hazard. Mater. 135, 210-217.

23. Perez, N., Sanchez, M., Rincon, M. \& Delgado, L. (2007). study of the behavior of metal adsorption in acid solutions on lignin using a comparison of different adsorption isotherms. Latin Am. Appl. Res. 37, 157-162.

24. Nemr, A.E. (2009). Potential of pomegranate husk carbon for $\mathrm{Cr}(\mathrm{VI})$ removal from wastewater: Kinetic and isotherm studies. J. Hazard. Mater. 161, 132-141.

25. Oladoja, N.A., Aboluwoye, C.O. \& Olademeji, Y.B. (2008). Kinetics and Isotherm studies on Methylene Blue Adsorption onto Ground Palm Kernel Coat. Turkish. J. Eng. Env. Sci. 32, 303-312.

26. Dang, S.V., Kawasaki, J., Abella, L.C., Auresenia, J., Habaki, H., Gaspillo, P.-A.D., Kosuge, H. \& Doan, H.T. (2009). Removal of arsenic from simulated groundwater by adsorption using iron-modified rice husk carbon. J. Water Environ. Technol. 7, 43-56.

27. Ho, Y.S., Mckay, G., Wase, D.A.J. \& Foster, C.F. (2000). Study of the sorption of divalent metal ions on to peat. Adsorpt. Sci. Technol. 18, 639-650.

28. Fonseca, B., Maio, H., Quintelas, C., Teixeira, A. \& Tavares, T. (2009). Retention of $\mathrm{Cr}(\mathrm{VI})$ and $\mathrm{Pb}(\mathrm{II})$ on a loamy sand soil Kinetics, equilibria and breakthrough. Chem. Eng. J. 152, 212-219. doi:10.1016/j.cej.2009.04.045. 